turns along the Indian Coast to north and north-west. This turning might cause considerable changes in the eonditions to be found during October-November and described above for the period here concerned.

\section{Currents}

Very obviously it would help greatly in the understanding of the oceanngraphical situations discussed above if it were possible to make observations of the speed and direction of the bottom water movements at regular and frequent intervals around the clocksay, every half-hour for a lunar day on a number of separated occasions. We had certain suitable apparatus of great simplicity for making such current observations, but time did not serve. Only a few spot observations were possible using the very simple instruments developed by one of us (J. N. C.), but a notable current one-third knot in speed was meas. ured running towards about $210^{\circ}$ magnetic. This was at the position lat. $18^{\circ} 51^{\prime} \mathrm{N}$., long. $72^{\circ} 29^{\prime} \mathrm{E}$., and served to show at least that the bottom water was not setting constantly towards the coast at the time. Perhaps it might have been found to set dominantly shorewards later after the north-east monsoon had become more strongly established. If so (and the matter should certainly be investigated), a mechanism explaining the shorewards uptilt of the layer of minimum oxygen would be to hand.

We wish to thank the participants in the refresher course in marine biology who were engaged in the collection of the observations; the Indian Navy for the provision of shipboard facilities, and Mr. K. Koli, who kindly allowed us to use his boat.

"Schott, G., "Geographie des Indischen und Stillen Ozears" (Boysen, Hamburg, 1935).

"Jayaraman, R., and Gogate, S. S., Proc. Ind. Acad. Sci., 45, 151 (1957).

${ }^{3}$ Gilson, H. C., "The Nitrogen Cycle", Rep. John Murray Exp., 2 (2),

\title{
RUSSIAN CONTRIBUTIONS TO THE INTERNATIONAL GEOPHYSICAL YEAR
}

T HERE are eighty-six scientific institutions in the Soviet Union taking part in the programme of the International Geophysical Year. They are organized by eighteen departments and ministries of whioh the most important are the Academy of Sciences, the Northern Sea Route Administration, the Hydrometeorological Service, and the Ministries of High Schools and Communication. The Soviet International Geophysical Year Committee publishes regularly an Information Bulletin giving details of the Russian investigations. It has also issued a bibliography of International Goophysical Year publications, arranged the issue of a series of commemorative postage stamps, and is preparing a fulllength popular scientific film in colour dealing with its contributions to the International Geophysical Year.

\section{Antarctica}

Particular attention has been given to Antarctic research. The Academy of Sciences set up an Antarctic Expedition in 1955 and has established three main stations : Mirny (near Haswell Island), Vostock (near the south magnetic pole), and Sovietskaya (near the pole of relative inaccessibility). The two inland stations are more than $1,400 \mathrm{~km}$. from the coast. There are also at present three further research bases. The Mirny Observatory carries out regular observations in nearly all the fields of the International Geophysical Year programme, such as meteorology, glaciology, oceanogxaphy, geomagnetism, ionospheric physics, seismology, and the study of cosmic rays and of Earth currents. The other stations are run on more modest lines.

A magnetic profile was made from Mirny to Pionerskaya, and from this the existence of a mountain ridge under the ice $250 \mathrm{~km}$. from the coast was inferred. This was confirmed by seismic and gravimetric investigations, which showed that the ice is $2,500 \mathrm{~m}$. thick in some places, and that substantial parts of the ground beneath the ice are below sealevel.

It was established that the Antarctic ice cap is shrinking, like that of the Aretic, but at a very much slower rate. The variation of temperature with depth in rocks was investigated, and in certain inland regions they were found to be frozen (that is, below $0^{\circ}$ C.) to a depth of $200-300 \mathrm{~m}$. Frozen rocks were found to thaw to depths of $0 \cdot 1-2 \cdot 0 \mathrm{~m}$. in surnmer.

Geologists studied the coastal region between $80^{\circ}$ and $110^{\circ} \mathrm{E}$. Exposed rocks are scarce there, and mainly old pre-Cambrian crystalline schist and gneiss, intersected by vast granite intrusions, were found. This confirms the theory that this region is part of a shield. Metamorphosed sands and conglomerates were also found in this region.

An air survey was made of the coastline between $40^{\circ}$ and $166^{\circ} \mathrm{E}$., and maps have been published of this area. Three expeditions studied ocean currents, using the electromagnetic methods of measurement, and sedimentation and bottom structure, in a large part of the Antarctic Ocean.

\section{The Arctic}

In the Arctic, too, there has been a great deal of activity, particularly on the drifting ice stations. It was found that in summer, atmospheric pressure is abnormally low in the central Aretic and this disrupts the normal ice drift. It was also found that the ozone concentration is very great in March. A com. paratively deep marine trench (up to $3,000 \mathrm{~m}$.) was found between Greenland and Spitsbergen, which is of importance in the flow between the central polar basin and the North Atlantic.

\section{Oceanography}

The non-magnetic ship Zarya voyaged extensively (including a trip from Leningrad to Indonesia, crossing the Atlantic six times and visiting Australia via 
Cape Town), and found anomalies even in the deep ocean, and determined the present position of the magnetic equator. The oceanographic ship Vityaz spent much time in the Pacific studying currents. It determined the boundary of the sub-arctic front between the Kuroshio and Oyashio currents, of the subtropical front between the Northern Trade drift and the North Pacific drift, and of the north (and south) tropical fronts between the Northern (and Southern) Trade drifts and the intertrade back drift. It found velocities of as much as $10-12 \mathrm{~cm}$. $/ \mathrm{sec}$. at $1,000 \mathrm{~m}$. in certain places (instead of an anticipated maximum of about $3 \mathrm{~cm}$. $/ \mathrm{sec}$.). A new trench was found north of the Fiji Islands, and a part of the Marianas Trench was found to have the record depth of $10,990 \mathrm{~m}$. Photographs of the ocean bottom were taken at depths of up to $9,800 \mathrm{~m}$.

\section{Rockets and Earth Satellites}

By June 1, 1958, three satellites had been put into orbit and fifty-nine rockets fired, including one which reached a height of $473 \mathrm{~km}$. From readings transmitted by the rockets the air pressure up to $260 \mathrm{~km}$. was determined - at $260 \mathrm{~km}$. it is of the order of $10^{-7} \mathrm{~mm}$. mercury. A mass-spectrometer was taken up and it was found that, between $105 \mathrm{~km}$. and $206 \mathrm{~km}$., the main ions present have a mass number 30 (which is interpreted as NO ions). Dispersion interferometers were also taken up to measure the electron concentration in the ionosphere. It was confirmed that there is no clear layer at an altitude of about $110 \mathrm{~km}$. but merely a region of maximum concentration of electrons. Beyond this the concentration of electrons falls slightly, and then increases to the $F$-layer, beyond which, contrary to the American observations, only a slow decrease was found. Animals were sent up in some of the rockets. They were recovered by parachute, and some of the animals made many trips. In the second satellite an animal was carried, and was found to behave normally in a state of free fall, and to manage well with other peeuliarities of cosmic flight, during the week in which the air-regenerating apparatus was functioning. Ionospheric measurements made with the satellites confirm the results obtained with rockets. Observations of cosmic rays were obtained by means of the satellites; their intensities differed from the predictions of the present theories about the Earth's magnetic field. From the orbits of the satellites the density of the air layers through which they were passing was calculated, and found in some cases to be several times larger than the predicted values.

The third satellite was a veritable cosmic laboratory. It could measure the number and energy of micrometeorites hitting it, and carried a mass spectrometer. It measured its own electric charge, and the charges of the layers it passed through. It registered the atmospheric density and pressure, and carried a selforientating magnetometer. It was also used for experiments on the control of orientation and internal temperature of the satellite vehicle.

\section{Zodiacal Light, Meteorites and Earth Currents}

An expedition to Egypt was organized to observe the zodiacal light and the polarization of the day. time sky, with specially developed instruments. These observations are being continued by the Helwan Observatory of the University of Cairo. The zodiacal light is also being studied at Aksenger, near AlmaAta, in the U.S.S.R. ( $44^{\circ}$ N., $76^{\circ}$ E.), and by comparing these observations with those from Egypt it will be possible to find out how the properties of the zodiacal light depend on the ecliptical latitude.

In the U.S.S.R. eight stations have used radar to observe meteoric activity, and several formerly unrecorded streams of meteors were found, on January 15 and 16,1958 , for oxample, and on February 14 and March $9-15$ of the same year. It was found that most sporadic meteors have elliptical orbits around the Sun, but some (less than 1 per cent of the whole) have been found which are definitely in hyperbolic orbits.

Earth-currents have been recorded continuously and pulsations of periods 1-4 sec. have been observed to occur simultaneously in the Arctic, Antarctic and middle latitudes. In the Antarctic large fluctuations occur in the amplitudes of the Earth potentials, up to about 1 volt $/ \mathrm{km}$.

\section{Seismology}

Seismic observatories were set up in the polar regions. There were six stations in the Arctic, and two in the Antarctic. These stations, in regions in which regular earthquake observations do not usually occur, give valuable information. The Antarctic stations observed about 600 earthquakes (in the twoyear period beginning June 1, 1956), of which about 70 had epicentres south of $40^{\circ} \mathrm{S}$. - however, no earthquakes have been detected which originated within the Antarctic mainland.

Microseisms were studied by many stations in the U.S.S.R. It was found that the microseisms observed in the European part of Russia originate mainly on the shores of Norway-no microseisms are observed when the storms are in the North Atlantic or on the shores of Greenland.

\section{Okhotsk Sea--Pacific Ocean Structure}

The crustal structure near the eastern coast of the U.S.S.R. was intensively studied. This region, extending to Kamchatka and the Kuril Islands, is of great interest. It has a high seismicity, with many shocks at all depths-this means that there is probably a deep major fault under the region. 'The deep seismic sounding method was used extensively; $3,300 \mathrm{~km}$. of seismic profiles were taken at sea. The preliminary results show that the crust has different structures under the Okhotsk Sea, the Kuril Islands, and the oceanic plateau, with a thickoning of the crust under the islands, and a substantial decrease of thickness under the oceanic plateau, where the crust is $12-18 \mathrm{~km}$. thick (including the depth of the water). This region was covered also by aeromagnetic and sea gravitational surveys, and large anomalies were found (about $4,500 \mathrm{~km}$. of sea gravitational surveys wero taken).

The U.S.S.R. organizes the World Data Centre $B$ for the International Geophysical Year: this has the task of collecting, keoping, and circulating data and results of all aspects of the work. Anyone wanting copies of such information should write either to Centre B1, Institute of Aeroclimatology, 33/35 Ulitsa Vorovskogo, Moscow; or Centre B2, Institute of Terrestrial Magnetism, 64 Chkalov Street, Moscow.

This article has been based on material supplied by Prof. V. V. Beloussov and V. A. Troitzkaya. N. A. Routuedae 